Association for Information Systems

AIS Electronic Library (AISeL)

\title{
The Impact of Digitizing Social Networks on Refugee Decision Making - The Journey to Germany
}

\author{
Safa'a AbuJarour \\ Universität Potdam \\ Lama Jaghjougha \\ University of Kent, Brussels \\ Mohammed AbuJarour \\ XU University of Applied Sciences
}

Follow this and additional works at: https://aisel.aisnet.org/wi2021

AbuJarour, Safa'a; Jaghjougha, Lama; and AbuJarour, Mohammed, "The Impact of Digitizing Social Networks on Refugee Decision Making - The Journey to Germany" (2021). Wirtschaftsinformatik 2021 Proceedings. 6.

https://aisel.aisnet.org/wi2021/VDigitization/Track05/6

This material is brought to you by the Wirtschaftsinformatik at AIS Electronic Library (AISeL). It has been accepted for inclusion in Wirtschaftsinformatik 2021 Proceedings by an authorized administrator of AIS Electronic Library (AISeL). For more information, please contact elibrary@aisnet.org. 


\title{
The Impact of Digitizing Social Networks on Refugee Decision Making - The Journey to Germany
}

\author{
Safa'a AbuJarour ${ }^{1}$, Lama Jaghjougha ${ }^{2}$, Mohammed AbuJarour ${ }^{3}$ \\ ${ }^{1}$ University of Potsdam, Business Informatics, Potsdam, Germany \\ safaa.abujarour@uni-potsdam.de \\ ${ }^{2}$ University of Kent, International Migration, Brussels, Brussels \\ 1j299@kent.ac.uk \\ ${ }^{3}$ XU University of Applied Sciences, Coding and Software Engineering, Potsdam, Germany \\ m.abujarour@xu-university.de
}

\begin{abstract}
The high reliance of refugees on digital tools has been the motor of digitization, which includes not only mobile applications, but also digitization of human aspects, namely, social capital (networks). Refugees tend to rely on their social capital (networks) to make well-informed decisions, especially related to the migration journey. An ideal supporting tool here has been Social Networking Sites (SNS). To investigate this topic, we have followed a qualitative approach and conducted 15 interviews with Syrian refugees in Germany. The analysis of our interviews has revealed four typical streams of utilizing social networks through SNS in the context of migration: (1) information gathering, (2) service consumption, (3) understanding the relevant procedures and systems, and (4) content creation and service provisioning. Our goal is to discuss the impact of digitized social networks on refugees aiming at maximizing the benefits, e.g., information gathering, and avoiding the risks, e.g., frauds.
\end{abstract}

Keywords: Digitization, Social Networks, ICT, Refugees, SNS, Social Capital

\section{Introduction: Refugee Social Networks}

The recent migration waves, especially from the Middle East, raise the need to study the new migration processes and the changes that have occurred in migration in light of the recent technological development. Since 2011, more than 5.6 million people have fled Syria searching for safe places [1]. Most of the Syrian refugees went to neighboring countries: Turkey, Lebanon, Jordan, Iraq and Egypt and others. Yet, other refugees decided to make their way to Europe. In 2015, around one million refugees arrived to Europe [1]. According to the International Organization for Migration (IOM), more than 970 thousand refugees arrived Europe by sea and about 34 thousand refugees arrived Europe by land in 2015 [2]. This situation has created a challenge among the European Union countries concerning the best strategy to resettle people, especially after the long and risky journey to the hosting countries. Decision makers had to propose a fair, feasible, and fast strategy to handle this 'crisis'. 
Yet, the more complex decision-making process lies on the side of the refugees seeking asylum in Europe. The decision by migrants to make this journey and to move to Europe is a tough one to make. During the migration journey, the experience of migrants and the decisions they make are complex processes, where searching for a safe place in which they can build a better life is a priority [3]. There are several factors that make this process a complex one: Risk, cost, legal constraints, and trust issues. Because of the complexity and criticality of this process, refugees tend to rely on their social capital (networks) to support their decision making. Social capital is a measure of the amount of networks person has built [4]. Therefore, we use the term social networks to capture the social capital of people.

Social networks represent trustful and reliable environments for refugees, to which they can refer for support whenever needed. Those networks typically consist of family members, relatives, and friends. The larger and more diverse one's network is, the more reliable that network is. In this context, the decision to migrate or where to migrate is not primarily based on economic and rational thinking only, but also on the information gathered about the availability of people who can support the migrant financially and psychologically during all stages of the migration journey and after reaching the final destination as assumed by the network theory of migration [3]. Social networks help in establishing "migration networks", which help in establishing social ties between the refugees in the country of destination and the prospective refugees who are still waiting to start their migration journey. In fact, every migrant provides opportunities for people from their social network to help them migrate as well.

Because the size and diversity of refugee social networks have a direct impact on their migration journeys, it is typically important for refugees to expand their social networks. For instance, refugees tend to consider the friends of their friends as part of their own social networks. This concept of "friends of friends" resembles very well with the core concepts of modern Social Networking Sites (SNSs). Therefore, it is not surprising that refugees rely largely on SNSs to digitize and expand their social networks.

Social Networking Sites are no longer simple personal tools used for entertainment, but they have rather evolved into a key source of information. Previous research has shown that this observation holds in particular true for refugees before and during their migration journeys [5]. Their reliance on SNSs and other Information and Communication Technologies (ICTs) has increased due to factors related to the forced migration from conflict zones, the need to communicate with their (geographically dispersed) families and friends, to collect information, and seek assistance during their migration journeys.

In this paper, we investigate the impact of digitizing refugee social networks by means of SNSs on their complex decision-making processes. Towards this goal, we used a qualitative approach where we interviewed 15 Syrian refugees in Germany. Our analysis has revealed four main categories of using SNSs for refugee decision-making: (1) information gathering, (2) service consumption, (3) understanding the relevant procedures and systems, and (4) content creation and service provisioning. 
The rest of this paper is organized as follows. In Section 2, we introduce related work on the social capital to support migration decision making and ICT-enabled tools to support the migration journey. In Section 3, we introduce our methodology and then we show our empirical evidence on how ICT solutions support migration decision making in Section 4. We discuss further topics related to our paper in Section 5. And summarize our paper in Section 6.

\section{Related Work}

\subsection{Social Capital to Support Migration Decision Making}

The social and economic dimensions affect the decisions that migrants, refugees, and asylum seekers make throughout their journeys to the destination countries. This makes the migration process complex; due to wars and conflicts, the dangerous flee journey, and finally to the resettlement after arriving at the host country [6;7]. Recently, researchers have been interested in uncovering the effects of social capital on the increasing international migration, especially considering that migrant networks are a form of social capital that people can rely on to access opportunities in the destination country [3]. This form of social capital consists of networks of connections of potential migrants that can be relied on to reach the destination country. Thus, the migrant networks of personal relationships that are formed by the connections between migrants and non-migrants can increase the possibility of international migration, affect the perpetuation of migration, and change the nature of migration patterns [3]. Moreover, social ties might lead as well to increasing in international migration because they provide financial assistance, psychological support, help with migration costs, and reduce risks until migrants reach the country of destination [8;9].

In general, social capital supports the decision making of migrants to pursue the migration journey for individuals who have strong relationships with members of their social networks due to two factors; declining costs and declining risks. Migrants who have strong ties to their social network and expand their social networks in the homeand destination-countries with reliable people can rely on them to help the migrants reduce the costs of the trip by providing advice and reliable information, including among others, the cheapest means of transportation, the most reliable roads to reach the destination, hotels, transportations, etc. [3;10].

On the other hand, declining risks is also related to reducing the risks of migration by providing a sense of security, support, and confidence in the presence of an auxiliary person during all stages of the migration journey [3]. Therefore, migrants often travel in groups from the same region or city of origin to reduce the risk and make them feel reassured in their journey toward reaching safe countries. This requires building trust networks with strong relationships of migrant networks that link current migrants, former migrants, potential migrants, and non-migrants in the countries of origin and the destination countries $[11 ; 12]$.

Despite the acknowledgement of the importance of ICTs in migration-related studies on a large scale, social sciences are still striving to integrate their convergence 
theoretically within the "network society" [13]. Permanent and constant development of ICT requires the establishment of continuous empirical studies to discuss updates in migration which are evolving with the continuous development of ICT. Therefore, scientific interest in migrants and refugees using ICT to communicate with their networks during the migration stages has increased; examining their journey in the country of origin, requiring assistance during the migration journey, and after their arrival in the destination country (e.g. [14]).

Research shows that the use of SNSs influences migration decisions, where SNS is now considered one of the most important communication channels that make migrants more aware of the possibilities and methods of migration and the directions of stability that suit them [14]. Technology plays an important role in the social networks of migrants as it positively affects social capital by strengthening connections between people and allowing them to expand their social networks [15]. ICT-enabled tools by migrants has been helping them in creating and maintaining social ties between destination countries and countries of origin. According to [16] several studies have addressed the impact of ICTs on migration processes $[17 ; 18]$. In the next section, we introduce related studies to using ICT-enabled tools and solutions to support migrants in their migration journey to the destination countries.

\subsection{ICT as a Medium to Support the Migration Journey}

Most refugees suddenly had to leave their homes carrying only their smartphones and little money - often just enough to reach their host countries. In cases of forced migration, ICT-enabled tools and solutions are vital to assist people on their journeys, for instance by enabling the communication with their social networks, locating and requesting help, and for general safety during the risky journey to the country of destination [19]. In some cases, the lack of mobile phone coverage could lead to dangerous threats, as migrants depend on their smartphones for asking for help and rescue, according to Lesvos Solidarity ${ }^{1}$. In addition, staying connected with migrants who have preceded and knowing the route to Europe is a crucial part of the must-have information for the migration journey [20].

For nowadays' migrants, charging their smartphones is more important than having food and water, as they consider it the only tool that will help them move to the destination country, as described by [21]. One of the main ICT usages by migrants during their journey to the country of destination is using SNS, as it is an important source of information in the migration decision-making process and to keep abreast of the latest changes in the roads leading to Europe. Moreover, SNS is a primary means for refugees to communicate with their families and access services such as translation, guidance, and navigation facilitation, and to learn about legal and organizational structures in the host country [22;23].

Refugees use ICTs in specific and simple ways that are easy for all of them to understand and share. For instance, Figure 1 shows the migration map "The Road to Germany - that many refugees circulated via WhatsApp during their

\footnotetext{
${ }^{1}$ https://lesvossolidarity.org/en/
} 
journey to Europe [10]. It shows the route and geographical stations that refugees can take from Izmir in Turkey to reach Germany, the total cost of the journey, the cost of each phase, the currency to be used, and the parts that refugees need to make on foot [10]. Additionally, ICT-enabled communication tools and social networking sites also enable establishing relationships between migrants and smuggling networks that may include (travel agents, lawyers, employment offices, translators, housing agents, and drivers to transfer them to collection points), which makes it a multilateral process [23; 24]. These networks are crucial to make the migration journey to the country of destination possible. Besides, "virtual migration network" has been created on SNSs, where migrants' participants report about their migration journeys, the routes, transportation, risks, and helpful advice [20]. All that can help future migrants in their journey to the destination countries. As a result, these social networks have contributed to the decision making and choices of the country of destination, based on the information of the experiences of previous refugees who arrive at the host countries $[10 ; 20 ; 25]$. For instance, this information includes the duration of asylum procedures in each country of destination, details on obtaining a residence permit, and information about family reunification duration and procedures.

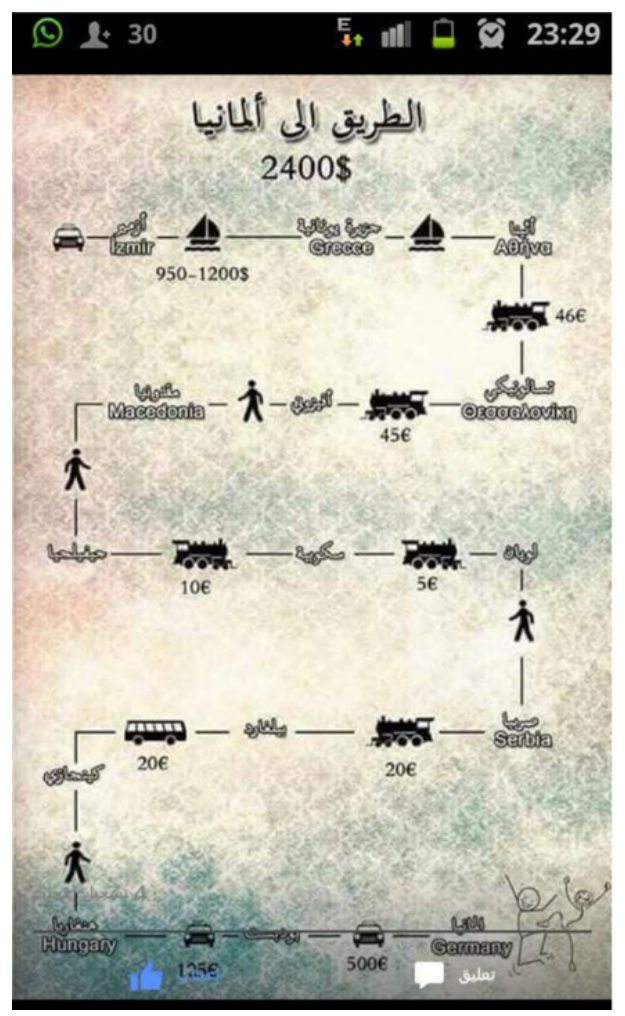

Figure 1. The Road to Germany - الطريق الى المانيا 


\section{$3 \quad$ Methodology}

Germany received the largest number of asylum applications among its European neighbors in 2015 with more than 476,000 asylum seekers [1]. Therefore, it is interesting to investigate how the refugees who arrived Germany during the latest refugee wave in 2015 used digital tools to achieve their goal of reaching Germany.

In this study, we followed a qualitative approach and conducted 15 semi-structured, face-to-face interviews with Syrian refugees in Germany. The goal is to collect more relevant insights about their stories to reach Germany and how ICT and their social networks helped them before and during the migration journey. All interviewees were recruited and conducted by the first author following a snowball sample. We asked our respondents questions related to the usage of their social networks to facilitate their journey to Germany. We specifically looked for themes reflecting the use of digitized social networks by our respondents and in which way these networks have been contributing to the success of their journey to Germany and to their integration into the society upon arrival. All interviews were initially conducted in Arabic, audio-recorded, transcribed, and then carefully translated into English. After iterative coding of the interviews using Atlas.ti, we could identify four main categories, including: (1) information gathering, (2) service consumption, (3) understanding the relevant procedures and systems, and (4) content creation and service provisioning.

Table 1 shows the demographics of our respondents. It is worth mentioning that the proportion of male/female is representative. As shown by [26], over two thirds (69.2 percent) of asylum applicants in Germany from the principal countries of origin in 2015 were male.

Table 1. Demographics of 15 Refugee Interviews

\begin{tabular}{cc|cc}
\hline Gender & & Education & \\
Female & 6 & High school or lower & 8 \\
Male & 9 & Bachelor or above & 7 \\
& & & \\
Age group & 4 & Current residency & 6 \\
$18-24$ & 3 & Shartment & 5 \\
$25-30$ & 6 & Temporary residence & 4 \\
$31-39$ & 2 & & \\
Above 40 & & & \\
\hline
\end{tabular}

\section{Empirical Insights: The Benefits of Digitized Social Networks}

"There are many specialized Facebook pages that collect the experiences of asylum seekers during their journeys including all details. [...] They alert us about police operations. They also report about the smugglers they had dealt with. [...] Although we come from another country, we knew the smugglers before meeting them, through the information on Facebook. When I arrived Greece, I had in mind taking the land path. Then, I changed the plan because I knew from others on Facebook that it was too 
difficult and that path was dangerous and not safe, especially, in Macedonia, Hungary, and Serbia. All of that was posted on Facebook. Right now, I can tell you that more than $95 \%$ of people who left used [advice from people on] SNS. " - an interview quote.

Based on our review of related work and the collected insights from Syrian refugees in Germany, we have been able to reveal four main streams, where digitizing social networks through ICT (mainly SNSs) supported the complex refugee decision making processes. These streams are: (1) Information gathering (mainly before the migration journey), (2) service consumption (during the journey), (3) understanding the relevant procedures and system (mainly upon arriving the country of destination), and (4) content creation and service provisioning. Each of these streams has its own specialties that affect the decision-making processes. Yet, the four streams have one aspect in common, namely, the reliance on social networks to make efficient decisions.

\subsection{Information Gathering}

It is important to understand that preparing to escape to Europe (or somewhere else) could be a dangerous step to make while being in Syria. Each party of the conflict needs people to support their actions, and therefore, they do not allow people simply to leave. On the contrary, trying to escape might be considered as a 'crime' that is punishable. In these circumstances, collecting the required information and taking the necessary preparatory steps to escape should be done within a circle of trust to avoid any further complications. During this phase, there are two key questions to be answered: (1) where to seek asylum and (2) how to prepare for the journey.

Where to seek asylum: Refugees start searching for information about the potential countries of destination before starting their asylum-seeking journeys. This simple task is not straightforward for them due to several challenges. First, there is too much information available describing the situations and processes at several potential countries of destination, yet the majority of this information is misleading. This information includes out-of-context information, rumors, out-of-dated information, incomplete information, and fake news. One of our interviewees described this stating: "[...] this information [on Facebook Pages] is not reviewed or approved. It is a matter of luck; the information might be correct or wrong." Second, there is too little information provided by official websites, which forces migrants and asylum seekers to collect the required information from other sources. Third, there are language barriers. Even the too little official information is not typically provided in the mother language of the asylum seekers making it less useful for them. One respondent stated: "This Turkish smuggler speaks Arabic, as well. His Facebook page is well-known and the largest one on Facebook. All the information posted on this page is most probably 95\% accurate." As a result, asylum seekers tend to rely on information provided by members of their social networks.

Utilizing refugee social networks to collect information about potential counties of destination is mainly done using SNSs. Our respondents reported various types of information that can be obtained through SNSs, such as planning the best route to Europe, gaining knowledge about how to get there, and choosing the most suitable destination country. Finally, staying in contact with their social networks in the country 
of origin and who have preceded them to the destination country. One interviewee expressed this clearly: "I used my smartphone mainly during the preparation for our trip to read the latest updates on Facebook about the stories of the refugees travelling from Turkey to Europe, such as the page 'Refugees to Europe'”. SNSs were used prior to the migration journey to stay up-to-date: "I used to ask them about the best way to leave Syria and reach Germany. People used to inform me through social networking sites, and the result is that I am in Germany now." One of our respondents explained how he used Facebook to obtain and share information while planning the migration journey: "Before travelling to Europe, I had subscribed to many Facebook pages that I could find and provide information about travelling to Europe."

Preparation for the journey: Because arranging the escaping journey is complex and might be dangerous, it is important that refugees consider each step in details. Typically, failing to escape is even more dangerous, because their intention to leave becomes public and reaches local authorities. Therefore, it is essential to secure all the required resources and information to ensure reaching at least the borders of Europe. One participant described this stating: "As soon as I had the intention of leaving my country, I started using Facebook. Up to now, it is the largest source of information with respect to crossing the way from Turkey to Greece." One interviewee revealed examples on how Facebook groups helped them to gather information about the logistics of the journey from their social networks: "I communicated with some people who left before me through Facebook groups, such as 'Refugees to Europe' group. And with people who tried several paths and experience in identifying the safe path at the right times."

Because the journey is dangerous and complex, migrants tend to pay attention to all details and collect as much information and stories as possible. One respondent mentioned: "We benefited from reading the stories of those who left before us to Germany via Facebook so that we learn from their experience and gather information about the road and avoid the mistakes that others had faced and find out the equipment and stuff needed for this journey and risks." Along the same line, another participant stated: "Without smartphones during the entire journey, it would have been too difficult. Our predecessors used to share the best practices with us; TODOs, Not TODOs, etc. This was a huge relieve for us during the journey."

Our research clearly shows that migrants seekers consider SNSs as the primary source of information, especially information based on personal experiences. Furthermore, SNSs enable users to communicate directly with the user who created the content and follow-up further if needed. One of our interviewees stated: "When I was in Syria, I was following the people who left before us to Germany and Europe and I was in touch with them through the Internet, through social networking sites, through Viber, and through WhatsApp."

\subsection{Service Consumption on the Move}

The migration journeys that refugees had to go through are unique. They are expensive, tedious, and dangerous. Furthermore, they face many legal constraints. Therefore, migrants rely to a large extent on their social networks to survive their journeys. "We 
have relied mostly on Facebook during our journey" reported on respondent. Our analysis shows three typical usages of social networks during the migration journeys: (1) communicate with facilitators, (2) obtain real-time directions, and (3) survive emergency situations.

Find and communicate with trusted facilitators: Our interviews showed the importance of using refugee social networks through SNSs during their migration journeys to find trusted smugglers, who facilitated their journeys. One respondent reported: "I knew the smugglers from Turkey to Greece through Facebook. Simply by visiting the [Facebook] group 'Immigration to Europe and Smuggling Routes",. Moreover, it was important to be able to communicate with smugglers via SNSs applications, because they function across borders. Another respondent stated: "We communicated with the smugglers through Facebook and WhatsApp." One crucial issue in this context is trust. Migrants typically do not know those smugglers and because this step is risky and involves large amounts of money, migrants tend to ensure they deal with a trusted smuggler. Using SNSs, previous migrants and refugees give "reviews" to smugglers they have dealt with. This information is then used by later migrants to determine with which smuggler they want to deal. One interviewee mentioned: "We used to communicate with other asylum seekers who had experience with smugglers, to avoid bad smugglers (fraudsters or those who sell human organs). This way, we avoided harmful facilitators.". Another factor that helped migrants select trusted smugglers is direct recommendation from members of their social networks. One respondent stated: "I was introduced to the smugglers who helped me to leave Turkey through friends and acquaintances."

Obtain real-time and contextual directions: Due to the unique nature of their journeys, migrants need real-time and context-relevant directions. Followed paths are typically dynamic, therefore, it is important for migrants to receive real-time information about the path they have to follow. Also, it is typical that some rules apply to families and not to individuals. Thus, what might apply for some migrants might not apply to others. Our analysis shows that migrants consider SNSs as the primary source of information about routes, especially information based on personal experiences. For instance, one interviewee noted: "Along the road, we were in contact with several groups on Facebook to ask about the next steps and ask for advice and directions. " Our analysis shows an interesting setup of combining both GPS (standard services) and social networks input (through SNSs). One respondent described this setup stating: "When we were crossing countries, we used GPS and we were in touch with others who went before us, through WhatsApp and Facebook, to know which roads were safe. We used to do the same with the people behind us."

Emergency: One of the vital benefits of utilizing social networks of refugees during their migration journeys is asking for help during emergency situations. The majority of our participants confirmed that the use of a smartphone saved them on the journey to Europe due to the possibility of seeking help and being rescued during their dangerous migration journeys. One of our respondents expressed the reliance on their social networks through SNS: "I used the smartphone in the middle of the sea when the engine of our boat was damaged. I called the smuggler and we called our families, and as we had an Internet connection, we posted what happened with us on Facebook and 
asked for help." Furthermore, volunteers have created specialized SNSs channels to provide direct support for refugees during their sea trips through virtual rescue groups. One respondent described this stating: "One example is the rescue group on Facebook that is used to track the refugees on their way. Before leaving, we used to inform them that we're leaving so that they call the police or coast guards in case of emergency."

\subsection{Understanding Relevant Procedures and Systems}

Every migrant provides opportunities for people from their social network to help them migrate as well. Having a trusted member of their social networks in the new home plays an important role for migrants, asylum seekers, and refugees to be ready to start the integration process. A successful integration process requires completing the asylum-seeking process, and understanding the important legislations and regulations. During this stage, our analysis shows three benefits of social networks upon arriving the country of destination: (1) Complete the asylum-seeking procedures, and (2) understand important legislations and system.

Complete the asylum-seeking procedures: It is important to understand that the asylum-seeking procedures are typically complex. Obviously, the entire procedures use the local language (e.g., German), which represents a considerable barrier for newcomers. Here comes an important benefit of social networks, where previous asylum seekers guide newcomers during the complex procedures. They even provide hints from their own experience. Our interviews show that refugees and asylum seekers tend to share their personal experiences to help similar cases with respect to various stages of the asylum-seeking process: "I don't personally know the people on the Facebook pages. They share their experiences about what happened with them; such as who arrived here, who went to the immigration office, whether Berlin is the best city to apply for asylum or it is better to apply anywhere else. You find answers to all questions that might come to one's mind, just like a dictionary that you use to search for any term."

Relying on the experience of previous refugees and asylum seekers through SNSs to complete one's procedures has been emphasized by several respondents. For instance, "Through SNSs, we knew that we had to apply for asylum at the police station in the Greek island." and "Upon our arrival to Greece, I contacted the people who left before us through WhatsApp, Viber, and Facebook to figure out what we had to do next."

Understand important legislations and system: One of the key challenges for asylum seekers upon their arrival to the new home is to learn a new system that is widely different from what they had been used to. They have to pick up important legislations to avoid unnecessary penalties. Because previous refugees and asylum seekers are familiar with the background of the newcomers, it is easy for them to quickly 'onboard' these newcomers without overwhelming them with regulations that are not relevant for them. A prime example of propagating this knowledge is the high number of SNS channels created by previous refugees and asylum seekers to provide this knowledge to newcomers in their mother language. For instance, "كراجات المشنططين (translated to Station of People on the Move), with more than 300,000 members. One 
interviewee stated: "The majority of this Facebook Group live already in Germany since 2013 or 2014. They have their own experiences."

\subsection{Content Creation and Service Provisioning}

One of the important benefits of SNSs in the context of facilitating the complex decision making processes for migrants is the ability to create content and provide services based on own's experience and knowledge. Given the lack of comprehensive information from trusted official content providers, the large portion of misleading information about asylum-seeking, and trust issues, migrants tend to rely on content created by other fellow migrants based on their own experiences that had qualified them to be domain experts in asylum-seeking. "I share information about my journey on Facebook to help others just like we had used similar help." - an interview quote.

Furthermore, refugees and asylum seekers are the best to identify missing services in the context of asylum-seeking process. A prime example is the process of applying for family reunification. One of our interviewees explained how his own struggle through this process motivated him to provide this service for free for other fellow asylum seekers, who might lack the required skills to do this process on their own: "I spent a lot of time struggling to book an appointment for my family in the German Embassy (in Lebanon or Turkey). Therefore, I have created a Facebook group through which I help people to book appointments for family reunification in the German Embassy in Turkey or Lebanon for free."

Refugees know that they are the main content providers in this context and therefore they spend time and effort to create relevant and up-to-date content for prospective migrants and asylum seekers. One respondent stated: "I learnt a lot from the experiences that I got from the people, who left before me. I shared my experience with the people who came after me. This is how such information and experiences keep propagating from one to another." Another interviewee echoed the same message emphasizing the role of SNSs in this context: "Through SNSs, we publish all what we have passed through and all our experiences so that others benefit from it just like we have done." As mentioned earlier, SNSs enable users to communicate with the content creator to clarify further details. For instance, one respondent mentioned: "When I arrived Germany, many people, who wanted to leave Syria, communicated with me and asked me many questions [about my journey]. They asked me to give them the name of a smuggler either in Macedonia, Turkey, or Hungary."

Another important insight is the ability of bridging the language barriers by providing the initial support from migrants from previous waves who share the same language of the current asylum seekers. For instance, the Arab community in Turkey played an important role to reduce the number of dangerous accidents while crossing the sea to Greece. One interviewee mentioned: "The admins of this group are Arabs in Turkey, who decided to establish this group to help [asylum seekers] traveling to Europe and reduce the deaths on the way. I knew this group through other Facebook groups and some Facebook friends." 


\section{Discussion}

The considerable reliance of migrants on using their smartphones to access SNSs has been one of the main characteristics of the recent refugee wave. It has been necessary for refugees not only to keep in touch with family and friends, but also to receive advice from members of their social networks, and to communicate with facilitators while crossing the borders of ten to twelve countries to reach the destination country. It is interesting to observe how migrants had been exchanging information and experiences from their journeys through SNSs, in order to provide meaningful information, reduce risks, and save the cost of the journey for fellow migrants. The main asset for migrants is trusted and meaningful information about the journey and the migration process.

This meaningful information represents the fuel of the migration decision-making process. Migration networks through SNSs have enabled creating and sharing the necessary information about safe routes, procedures at destination countries, and further details relevant to asylum-seeking process. Migrants and refugees tend to form "virtual" social networks on SNSs to exchange information, and rely mainly on trusted social ties and personal experiences from those who preceded them a few months, days, or even hours prior, and believe that this method protects them from fraud and misleading information. Therefore, many migrants are keen to stay online by connecting to $\mathrm{Wi}-\mathrm{Fi}$ hotspots or buying SIM phone cards in every country they cross to receive advice from their social networks and to be informed about the latest developments related to the route to destination.

Due to the intensive usage of smartphones by migrants and refugees, they prefer to use SNSs to communicate with and obtain information from their social networks that are known and trusted for them. They look to the different experiences of members of their social networks (e.g., friends or families), where these experiences are largely embraced and considered as a trusted source [20]. Trust plays an essential role in this context, therefore, migrants used to compare information from different channels to evaluate their quality. One interviewee mentioned: "When I used to ask about a specific route through different SNSS and get several answers, I was comparing the answers I got through Facebook, Viber, and WhatsApp, and I took the common answer among the different sources." This is one of common techniques that refugees typically use to avoid getting trapped by fake news, rumors or misinformation. This kind of false information might lead to bad decisions during the migration journey. Another technique that refugees tend to use to avoid the obvious risks associated with the use of digital SNS, such as, fraud, or attacks by anti-migration groups is engaging in closed groups where strict rules are followed by group admins to filter anti-migration content and users.

It is worth mentioning that information needs have special requirements in this context. This information is critical to human lives, has direct impact on financial cost, and has a dynamic nature. Additionally, there are legal constraints that apply to this situation, trust issues that affect the creditability of the information, and language barriers to make the information digestible. Therefore, personal experiences and direct social connections play a crucial role. One respondent stated "When I told a friend of mine in Syria that I was planning to come to Germany, he told me that one of his 
relatives had recently left to Germany. He connected us together so that I can learn from his experience."

Social networks of migrants, as part of their social capital, positively affect not only their migration journeys, but also their integration process in the new homes. For instance, by facilitating their entrance to the job market and providing information on job opportunities in the host countries [27; 28; 29] In this context, researchers have found that almost half of Germany's migrant population relied on interpersonal contacts to obtain job opportunities [27]. Moreover, refugees and migrants with strong relations to the local social networks have better opportunities to access cultural knowledge that contributes to facilitating their integration into social environments and provides the opportunity to participate in the civil society $[30 ; 31]$.

Our analysis reveals useful implications for several stakeholders and target audiences relevant to refugee topic. These include:

1. Governments and decision makers, to apply and support e-government solutions in reaching refugees to inform them about the rules and regulations, and possible integration opportunities

2. NGOs and the local community, to inform them about possible usages of ICT to foster the integration process between them and refugees by providing online means to exchange skills on culture, language, etc.

3. Researchers and academics, who are interested in researching topics related to digitalization, social capital, social networks, crowdsourcing with respect to vulnerable groups, in particular migrants and refugees

\section{Summary}

The complex decision-making processes that migrants and refugees have to perform are typically exacerbated by lacking meaningful information from trusted sources. Therefore, they rely on their social networks to acquire the required information and to seek support along their migration journeys. Because larger and more diverse social networks mean higher chances of succeeding the migration process at low cost and low risk, migrants expand their social networks before starting their journeys. An ideal supporting tool here has been Social Networking Sites (SNSs), e.g., due to the concept of "friends of friends", the ability to contact content creators directly for further clarifications, and the crowd impact.

Migrants and refugees rely on their social networks, especially through SNSs, that enable them to maximize the benefits of their social networks. In this context, we had identified four streams of utilizing social networks through SNSs by migrants, namely, information gathering (mainly before the migration journey), service consumption (during the journey), understanding the relevant procedures and system (mainly upon arriving the country of destination), and content creation and service provisioning. Social networks of migrants and refugees, as part of their social capital, have a positive impact not only on their migration journeys, but also on their integration process in the new societies, which is an important goal of local authorities, organizations, locals, and all members of the societies. 


\section{References}

1. UNHCR: Persons of concern. Retrieved from http://popstats.unhcr.org/en/persons_of_concern (2020)

2. IOM: Irregular Migrant, Refugee Arrivals in Europe Top One Million in 2015. IOM Retrieved from https://www.iom.int/news/irregular-migrant-refugee-arrivals-europe-topone-million- 2015-iom (2015)

3. Massey, D. S., Arango, J., Hugo, G., Kouaouci, A., Pellegrino, A., Taylor, J. E.: Theories of International Migration: A Review and Appraisal. Population and Development Review (1993)

4. Paldam M.: Social Capital: One or Many? Definition and Measurement. Journal of Economic Surveys, 14(5):629-53 (2000)

5. Abujarour, S., Krasnova, H.: Understanding the Role of ICTs in Promoting Social Inclusion: The Case of Syrian Refugees in Germany. In: European Conference on Information Systems Guimarães, Portugal (2017)

6. Koser, K.: Asylum Policies, Trafficking and Vulnerability. International Migration 38 (3):91-111 (2000)

7. Doornbos, N., Kuijpers, A. M., Shalmashi, K.: Refugees on Their Way to a Safe Country. The Netherlands: Centre for Migration Law, University of Nijmegen (2001)

8. Massey, D. S., Durand, J., Malone, N. J.: Principles of operation: Theories of international migration. The new immigration. An interdisciplinary reader, pp. 21-33 (2005)

9. Haug, S.: Migration Networks and Migration Decision-Making. Journal of Ethnic and Migration Studies 34 (4):585-605. (2008)

10. Gillespie, M., Ampofo, L., Cheesman, M., Faith, B., Iliadou, E., Issa, A., Skleparis, D.: Mapping refugee media journeys: Smartphones and social media networks. (2016)

11. Brettell, C. B., Hollifield, J. F. (Eds.): Migration theory: Talking across disciplines. Routledge (2014)

12. Granovetter, M.S.: Economic action and social structure: the problem of embeddedness. American Journal of Sociology 91 (3), 481-510 (1985)

13. Borkert, M., Cingolani, P., Premazzi, V.: The State of the Art of Research in the EU on the Take up and Use of ICT by Immigrants and Ethnic Minorities. Luxembourg: Office for Official Publications of the European Communities (2009)

14. Dekker, R., Engbersen, G., Faber, M.: The use of online media in migration networks. Population, Space and Place, 22, 539-551 (2016)

15. Alam, K., Imran, S.: The digital divide and social inclusion among refugee migrants. Information Technology \& People (2015)

16. Kozachenko, I.: Horizon Scanning Report: ICT and Migration. Working Papers of the Communities \& Culture Network+, 2 (2013)

17. Hiller, H. H., Franz, T. M.: New ties, old ties and lost ties: the use of the internet in diaspora. New Media \& Society, 6(6), 731 (2004)

18. Parham, A. A.: Diaspora, community and communication: Internet use in transnational Haiti. Global Networks, 4(2), 199-217 (2004)

19. Gillespie, M., Osseiran, S., Cheesman, M.: Syrian refugees and the digital passage to Europe: Smartphone infrastructures and affordances. Social Media+ Society, 4(1), 2056305118764440 (2018)

20. Dekker, R., Engbersen, G., Klaver, J., Vonk, H.: Smart refugees: How Syrian asylum migrants use social media information in migration decision-making. Social Media + Society, 4(1), 2056305118764439 (2018) 
21. Brunwasser, M.: Migrant essentials extend to smartphone'. International New York Times. Retrieved from https://www.nytimes.com/2015/08/26/world/europe/a-21st-centurymigrants-checklist-water-shelter-smartphone.html (2015)

22. AbuJarour, S., Krasnova, H., Hoffmeier, F.: ICT as an Enabler: Understanding the Role of Online Communication in the Social Inclusion of Syrian Refugees in Germany", European Conference on Information Systems, Portsmouth, UK (2018)

23. Schreieck, M., Zitzelsberger, J., Siepe, S., Wiesche, M., Krcmar, H.: Supporting Refugees in Everyday Life- Intercultural Design Evaluation of an Application for Local Information. PACIS 2017 Proceedings (2017)

24. Alkousaa, R., Popp, M.: European Purgatory: Migrant Smugglers Helping Refugees Return to Turkey. SPIEGEL ONLINE, Retrieved from http://www.spiegel.de/international/europe/why-refugees-in-greece-are-trying-to-go-backto-turkey-a-1100452.html (2016)

25. Dekker, R., Engbersen, G.: How social media transform migrant networks and facilitate migration. Global Networks, 14(4), 401-418 (2014)

26. Juran, S., Broer, P.N.: A Profile of Germany's Refugee Populations. Population and Development Review, 43: 149-157. https://doi.org/10.1111/padr.12042 (2017)

27. Drever, A. I., Hoffmeister, O.: Immigrants and social networks in a job-scarce environment: The case of Germany. International Migration Review, 42(2), 425-448 (2008)

28. Lancee, B.: The economic returns of immigrants' bonding and bridging social capital: The case of the Netherlands. International Migration Review, 44, 202-226 (2010)

29. Lancee, B.: The negative side effects of vocational education: A cross-national analysis of the relative unemployment risk of young non-western immigrants in Europe. American Behavioral Scientist, 60(5-6), pp.659-679 (2016)

30. Cederberg, M.: Embodied cultural capital and the study of ethnic inequalities. In L. Ryan, U. Erel, \& A. D'Angelo (Eds.). Migrant capital: Networks, identities and strategies. Migration, diasporas and citizenship (pp. 33-47). Basingstoke: Palgrave Macmillan (2015)

31. Elliott, S., Yusuf, I.: 'Yes, we can; but together': social capital and refugee resettlement. Kotuitui: New Zealand Journal of Social Sciences Online, 9(2), 101-110 (2014)

32. Gelb, S., Krishnan, A: Technology, migration and the 2030 Agenda for Sustainable Development (2018) 